\title{
Implementation and evaluation of teaching of College English
}

\author{
Runhua YANG \\ Chengde TV University \\ Chengde,Hebei 067000, China
}

\author{
Xiaodong SUN \\ Chengde TV University \\ Chengde,Hebei 067000, China
}

\begin{abstract}
The teaching evaluation as a means of teaching evaluation is being paid more and more attention to domestic educators. From the point of view of English teaching evaluation, the article takes teaching evaluation application as a starting point in co-operation between the teaching activities of China and the UK in order to explore the strategies to implement the teaching evaluation, it analyzes the effect of the application of the evaluation methods in the teaching, and it thinks of the problems that exists and makes a preliminary coping strategies.
\end{abstract}

\section{Keywords-) teaching evaluation; college English; Implementation}

\section{INTRODUCTION}

Our English teaching has made great progress through the efforts of educational institutions as well as national education personnel in our country, but at the same time with cheering for progress, we must not forget that English teaching-related issues are now present. The most serious problem is imbalances of the English regional development, which is not only reflected on region but also in the same area between different schools, and education unbalanced development between regions depends on economic and emphasis on the development of education, however, unbalanced development between different schools is mainly due to excessive gaps and learning ability of students, to tell the truth, unbalanced regional development will greatly affect the improvement of China's overall education level; secondly, there are still over-emphasis on the process of learning English scores while they are ignoring the procession in CET teaching, some college English teachers only teach book knowledge to students, while they are ignoring the cultivation of students' thinking skills and proficiency, which violates the purpose of education itself, Such teaching methods easily lead students to just writing ability to be strong, but their expression is weak, which resulted in that the community colleges can not input more practical talents; there is a very serious problem in college English teaching that lacked teachers and a Jiao Shiou often teaches a lot of students in the teaching process, teachers can not remember the students' name, even they pay attention to their study, college English teacher face heavy teaching pressure, it sometimes easily leads teaching to appearing to be inadequate, and some teacher qualifications are low, and the school can not provide training opportunities for them, finally, the ability of teachers can not get a reasonable increase.

On the current trend of rapid development in university education, the college English teaching is lagging behind, many universities still take the traditional teaching model, which can not be good innovation, the traditional teaching evaluation confined on the final exam papers, it is extremely unfavorable for them to fully exploit the students' abilities in different aspects, which results in the lack of the diversity of student development, only to change their evaluation in accordance with the traditional approach to improve their ability is unfavorable, which would also have negative influence on teachers' comprehensive and objective analysis to their students, and it makes it impossible to train outstanding students in one area. It is particularly important to think about university teaching effectiveness evaluation, and it will help to change the weakness of current university evaluation, which is greatly in line with the scientific development concept and promotes the development of college English teaching

\section{CONCEPT AND CONTENT OF TWO TEACHING EVALUATION}

Before we explore how to establish a scientific and effective English teaching evaluation system, you need to make sure concept and meaning of the article talking about "teaching evaluation" First, although this paper uses the" comment ", but we ill not strictly separate the" assessment "and" evaluation ". The term often uses "evaluation" in educational research, because" evaluation" can be prominent about judgment values in the process and value orientation of the judge, especially the value of education related to social policy and economy culture and the people's development. However, we often do not distinguish between the two words in the teaching practice, and we use the use evaluation more than "assessment". "Teaching Requirements" uses the more popular "teaching evaluation." Even though, when "teaching evaluation" workers are making criteria and making a judgment, it will reflect in its educational values.

Secondly, what the article talking about how between "teaching evaluation" and "Course Evaluation" relationship is? It is narrow "Curriculum Evaluation" in the traditional sense, which means that when people improve lesson plans 
and books, students make the activity or process of students' learning values, in general, including the evaluation of the objective system, the evaluation of lesson plans, the evaluation of curriculum standards, the evaluation of teaching and other core content, and its implementation is generally evaluated by specially trained staff who carried out dedicated evaluation methods and techniques.

In recent years, with the development of pedagogy and promotion of curriculum reform, more and more scholars define curriculum evaluation in a broader sense, which includes the education evaluation of "student evaluation, teacher evaluation, narrow curriculum evaluation, school evaluation field evaluation activities of all evaluations " Specifically ,broad curriculum evaluation including the assessment of students' psychological characteristics 、 learning methods and learning effect v the evaluation of teachers teaching behavior、 personality characteristics and teaching technology. Thus, a broad curriculum evaluation system can better reflect the essence of a comprehensive assessment in the curriculum and teaching process, it is more conducive to promote the development and reform programs.

After twenty years of development, the university has grown from a single English language teaching courses to a comprehensive curriculum especially in education reform in recent years. Formulate College English Curriculum objectives are based on the needs analysis of large-scale social English skills; content of college English teaching continues to expand, covering the language skills and knowledge of learning strategies, literacy, cross-cultural communication ability; college English teaching materials and teaching system are more and more diverse, and teaching mode and teaching methods are making reform and innovation. Therefore, "teaching evaluation" what this article discussed is essentially a "curriculum evaluation" generalized, because comprehensive evaluation about college English courses should include the curriculum evaluation system itself, but also teachers and students evaluation of the teaching process, teaching attitudes and methods of teaching effects.

\section{SituAtion OF COLLEGE ENGLISH TEACHING EVALUATION ANALYSIS}

\section{A. Formative Evaluation Summary}

As the article mentioned earlier, formative assessment is the most effective way to achieve pro-school evaluation. To understand the formation of current foreign language teaching evaluation study in our country, we searched papers about the formative evaluation (assessment) in CNKI pool the published between 1979 and 2009. As can be seen, research on formative evaluation of university English concerns about the evaluation of the comprehensive ability of foreign language, speaking and writing skills evaluation, self-learning ability evaluation, namely power evaluation, self-learning ability assessment, computer and network assessment, evaluation methods research and university English course evaluation . Evaluation tools which has used include classroom observation, case studies, discussion, feedback, interviews, student self-assessment and peer assessment, student diaries and reports, study archives, showcase student work, questionnaires, teacher evaluation, teacher diaries and examinations. It is mainly involved in the evaluation of teachers and students. Studies from different angles affirm the role of formative assessment to promote learning and improve teaching quality. But some studies have found no significant overall increase student or a single level of English, and it is different for different levels of students to make the validity of evaluation tools.

Analysis showed that the researchers focused more on the implementation of formative assessment, which includes the use of evaluation tools, evaluation level of development, formative assessment in the network and remote education, evaluation the quality assurance system, self-learning ability assessment, learner emotion objective evaluation.

Since then, the number of research papers clearly showed a rapid upward trend. Research based on student assessment, including oral and written evaluation, self-learning ability evaluation, and researches various evaluation instruments. Evaluation of the network environment gets concern, because electronic files and other formative means can be used more effectively at the aid of information technology. However, formative assessment research of listening and reading skills number is small, they lack teaching evaluation study and the number of course evaluation is less. In addition, researchers pay more attention to the practice of formative assessment, theoretical research is relatively weak, only individual paper discusses the problem about formative evaluation of the validity of the evaluation system and so on from a theoretical level.

\section{B. Model of College English Teaching and investigation evaluation}

We investigate people in order to understand the use of college English teaching and curriculum evaluation model and views on teaching and teacher evaluation model. Data analysis showed that teaching model based on computers and classroom has been implemented in a number of institutions, teachers hold a positive attitude towards the model, they think online teaching applies to listening skills, and it promotes the culture of self-learning ability. At the same time, teachers are keenly aware that reform teaching model puts forward higher requirements to them. However, advantages of network teaching have not been fully realized, for example, it give inadequate attention the cultivation of students' cooperative learning ability, and we should further strengthen the interactive between online teachers and students.

From the evaluation, the current emphasize on the detection of teaching, more people use the form of the examination, observation and interviews. Teachers understand and agree the promoting role of formative evaluation in teaching, but they consider specific implementation has some difficulties; currently, it doesn't have enough examinations about students' learning goals, learning plans, learning attitude, motivation, interest and autonomy, and it uses less new evolution such as the detection of insufficient portfolios, student diary evaluation 
tools. In the open part of the problem, the teachers point out that the new teaching model have high demand for selflearning ability, but currently students' abilities in this area is weak, it should strengthen formative assessment in order to promote students to improve self-learning ability; teachers also pointed out that large classes make teachers not track evaluation all students, thus implementing formative assessment has some difficulties.

\section{C. language testing and evaluation program survey}

We investigate a university to understand the use case of college English teacher evaluation theory and knowledge. Data analysis showed that the theory and practice of language testing is the focus of teaching, teaching time is significantly more than the time of statistics and measurement and student classroom practice time. The undergraduate course emphasizes on testing practices, teacher courses emphasize on testing theory, but the difference was not significant. Specific teaching points include: validity and reliability, as well as theoretical and practice and multiple-choice questions, questions difficulty and discrimination, the examination of data analysis and interpretation. Secondly, the level of testing, construct validity, content validity, internal consistency papers, score reliability, syllabus and rules, questions classification, skills testing, examination aftereffect, basic statistical concepts (such as the mean, standard deviation, $\mathrm{n}$ state distribution) and so on are important things in teaching. Low-risk test, the new assessment, language teaching items the purpose assessment of the theory and practice of teaching is weakest link in teaching, the former theory and practice of statistical measurement is also an urgent need to strengthen teaching content.

Our language tests began to gradually establish its status as a separate subject areas of applied linguistics in the early 1990s, therefore, language testing and evaluation of programs with a short history have the rapid development, it has been opened in the university in a wide range of different types and levels. Courses are mainly about Introductory, they are less high-end research programs. Overall teachers are strong, teaching is on the main by teachers, less students have practice, covering the main areas is teaching theory and practice. The survey found that the course of the evaluation should further enrich the theory and practice of teaching content, language teachers pay more attention to feedback in order to guide and promote the evaluation of teaching; in addition, the curriculum should better cover the forefront of the field theory and practice. From the international language test development trend, we have entered the post-modern psychology - sociolinguistic development stage (Spolsky, 1995), we need to think more about the impact on teaching and testing from a point of view of sociological, and the test of language teachers and evaluation of the knowledge and ability is the key factors to deal with this transformation. Inbar-Lourie points out that we need to focus on language teachers' evaluation knowledge and the research and training of ability. Moreover, we need to strengthen the exchange of faculty, we should write more in line with China's reality, to meet the different levels and needs of language testing and evaluation of materials in different institutions types in order to better adapt to the testing and evaluation of foreign language teachers professional training needs.

\section{SIGNIFICANCE OF IMPLEMENT TEACHING EVALUATION}

Teaching evaluation focused on the process of learning, and it focuses on student learning experience. Teachers can also adjust their teaching schedule by teaching evaluation to improve teaching methods. Teaching evaluation promotes teaching methods to change, and it provides timely feedback on teaching, teachers and students can discover the teaching process problems.

\section{CONCLUSIONS}

Teaching evaluation emphasizes students make continuous observation and interpretation of their own learning process through self-evaluation evaluation, and they make self-reflection and experience success in the learning process. We train students about self-monitoring, selfevaluation skills, students self-learning ability from cognitive, emotional v communication 、 self-management and other aspects of students. Teaching evaluation is an important part of teaching and learning for teachers and students, it is an integral part of English teaching evaluation, it is beneficial to change the traditional assessment which emphasis only on the results not the process and it helps to change the current exam-oriented education in the classroom teaching model. Therefore, to pay full attention to teaching evaluation, on the one hand it is to improve the ability of teachers to design scientific and practical assessment strategies; on the other hand, teachers should continue to study the evaluation feedback, while providing constructive feedback for students, at the same time, they make their timely manner adjustment of teaching, which truly serves the teaching evaluation.

\section{References}

[1] Tang Xiongying, Zhang Quan. The implementation and problems of the new evaluation in university English Teaching [J] Foreign language and foreign language teaching, 2007, 01:14-19.

[2] Zhang Mei. Formative self-evaluation based on student's lifelong learning culture studies [J] Chongqing University (Social Sciences), 2010, 01: 140-144.

[3] Zhang Rong. Study on Application of formative assessment in English Teaching in University [J]. Ningbo University (Educational Science Edition), 2011, 02: 101-105.

[4] Chen Yuanliang. Formative Assessment in College English Teaching implementation [J] Capital University of Medical Sciences (Social Sciences), 2011, 00: 208-209.

[5] Jin Yan. About College English Teaching Reform: Evaluation and teaching [J] Chinese language education, 2008, 03: 57-66 + 82-83.

[6] Zhang Nan. Study on Application of formative assessment in English Writing Teaching in the University [J] Intelligence, 2014, 33: 247. 